\title{
Territórios existenciais ético-estéticos em saúde coletiva
}

\author{
Silier Andrade Cardoso Borges ${ }^{\star}$ \\ Universidade Federal da Bahia, Salvador, BA, Brasil
}

Resumo

Este texto investiga as possiveis contribuições da filosofia para a problematização de questões em Saúde Coletiva, ressaltando os efeitos dos atravessamentos entre disciplinas habitualmente tidas como estrangeiras entre si. Busca-se ressaltar a dimensão da construção conceitual e a noção de territórios existenciais no campo filosófico, de modo a contribuir para a práxis no campo da Saúde Mental. Deste modo, discute-se a contribuição da filosofia para pensar o sofrimento psíquico, evidenciando a potência da clínica antimanicomial na construção de espaços que fabriquem sujeitos desinstitucionalizados. Para tanto, esboça horizontes ético-estéticos entrelaçados com os pensamentos de Gilles Deleuze, Félix Guattari e Michel Foucault.

Palavras-chave: filosofia; saúde coletiva; saúde mental; territórios existenciais.

\section{Ethical-aesthetic existential territories in collective health}

\begin{abstract}
This paper investigates possible contributions of philosophy for the problematization of Collective Health issues, emphasizing the effects of the approach among disciplines usually held as being different from one another. The purpose is to emphasize the dimension of conceptual construction and the notion of existing territories in the philosophic field, in order to contribute towards the practice in Mental Health. In this manner, the contribution of philosophy is discussed to think psychic suffering, evidencing the power of the anti-asylum clinic in the construction of spaces that manufacture deinstitutionalized subjects. To this end, ethicalaesthetic horizons are presented from the thoughts of Gilles Deleuze, Félix Guattari and Michel Foucault.
\end{abstract}

Keywords: philosophy; collective health; mental health; existential territories.

\section{Introdução}

O Sistema Único de Saúde (SUS), oriundo das lutas democráticas e populares inseridas no projeto da Reforma Sanitária Brasileira, configura-se em uma rede de ações e serviços para promoção, proteção e recuperação da saúde, garantida através do acesso universal e equânime de suas ações. No entanto, a realidade atual interpõe ao SUS questões múltiplas referentes ao subfinanciamento da saúde, desarticulação dos espaços de gestão, clientelismo e fisiologismo, prejudicando a tessitura do modelo de atenção integral (PAIM, 2009).

No âmbito da Saúde Mental, campo da reabilitação psicossocial dos usuários dos serviços substitutivos, nota-se que os discursos cotidianos dos profissionais de saúde costumam circular na incompreensão do SUS como seguridade, desvalorização profissional, rotatividade e terceirização no serviço público, inadequação do perfil e compromisso com o serviço público, desarticulação entre a Atenção Primária à Saúde e os serviços substitutivos, fragilização do controle social ${ }^{1}$ e inaptidão das instâncias micropolíticas e macrossociais em reorientar a formação acadêmica e pós-graduada segundo as necessidades contemporâneas, conforme as mutações técnico-científicas de nossa época.

\footnotetext{
^Endereço para correspondência: Instituto de Saúde Coletiva - Universidade Federal da Bahia. Rua Basílio da Gama, s/n - Campus Universitário do Canela. CEP: 40.110-040. Salvador-Bahia.E-mail: silier@outlook.com

'O conceito de "controle social" apresenta uma dupla acepção. No âmbito da saúde, representa as instâncias colegiadas instituídas pela Lei $\mathrm{n}^{\circ}$ 8.142/1990 (BRASIL, 1990b), que versa sobre a participação popular na gestão do SUS através dos conselhos e das conferências de saúde. Há também a concepção filosófica de "controle social" como instância de normalização e quadriculamento dos corpos, suscitando obediência produzida a partir do entrecruzamento entre poder e saber (FOUCAULT, 1987) ou, em outros termos, serialização através da convergência múltipla dos agenciamentos da subjetivação (GUATTARI; ROLNIK, 2011). Neste momento, utilizamos a primeira acepção.
}

Este trabalho convoca à saída dos nossos territórios discursivos, habitats de territórios semióticos, acrescentando outras possíveis vegetações: pode o saber filosófico contribuir para as discussões imanentes, possibilitando a produção de caminhos que proponham a resolução de questões em saúde? Quais são os efeitos resultantes da tranversalização de disciplinas habitualmente tidas como estrangeiras entre si? A construção desse diálogo pressupõe o abandono do modelo explicativo de causalidade linear, estabelecendo linhas de fuga dos paradigmas hegemônicos.

Não se trata de articular filosofia com a saúde, contabilizando semelhanças e diferenças segundo uma perspectiva arborescente, mas estabelecer possibilidades de práxis em saúde a partir de pontos de tangenciamento e ruptura, ofertados pelos diferentes modos de semiotização, de forma a ressaltar a dimensão de construção conceitual. Nesse sentido, acreditamos que este trabalho esboça dispositivos capazes de multiplicar os olhares sobre a saúde. Para tanto, torna-se relevante suscitar a discussão das questões atuais concernentes ao atravessamento das disciplinas, fabricando horizontes conceituais a partir dos entrelaçamentos ético e estético de Gilles Deleuze, Félix Guattari e Michel Foucault.

\section{Implicações e imbricações da construção de conceitos em saúde}

Observa-se que a atividade da filosofia não é refletir, uma vez não ser necessário ser filósofo para refletir sobre algum tema. Também não é comunicação, porque não objetiva criar consensos ou contemplação, restrição de quem vê objetos preexistentes. A atividade filosófica se faz com a criação dos conceitos. Portanto, o filósofo é aquele que detém o conceito em potência. Considerando-se 
que não há céu para os conceitos, não é possível resgatar o platonismo dos conceitos transcendentais e universais, mas fabricá-los enquanto acontecimento, a partir de suas múltiplas possibilidades, habitando um plano referencial e imanente que dialoga com outros planos. Toda criação conceitual é histórica, contextual e singular, sempre uma singularidade (DELEUZE; GUATTARI, 1992). Vontade em potência, vida conceitual que se cria e se transforma:

Por que é necessário criar conceitos, e sempre novos conceitos, por qual necessidade, para qual uso? Para fazer o quê? A resposta segundo a qual a grandeza da filosofia estaria justamente em não servir para nada é um coquetismo que não tem graça nem mesmo para os jovens. [...] Se há lugar e tempo para a criação dos conceitos, a essa operação de criação sempre se chamará filosofia, ou não se distinguirá da filosofia, mesmo se lhe for dado um outro nome. (DELEUZE; GUATTARI, 1992, p. 15).

O conceito, sempre fabricado, inventado a partir da assinatura das mãos que o cria (personagem conceitual), nunca permanece o mesmo quando transversaliza outros conceitos. O conceito não é ilha, mas ponte movediça duplicada, triplicada ou quadruplicada: um conceito não faz referência sempre ao si-mesmo, mas referencia outros componentes, sendo ele próprio a articulação de componentes diversos. O conceito pode se enraizar como árvore (paradigma arborescente), que pressupõe unidade, hierarquia e rigidez, ou pode se tornar rizoma, fluxos subterrâneos capazes de dissertar sobre os fenômenos sociais naquilo que eles apresentam de múltiplo, descentrando os registros de análise (DELEUZE; GUATTARI, 1995).

Há uma faceta pedagógica do conceito: "todo conceito remete a um problema, a problemas sem os quais não teria sentido, e que só podem ser isolados ou compreendidos na medida de sua solução" (DELEUZE; GUATTARI, 1992, p. 24). Logo, a condição de possibilidade de um conceito é, dentre outros, a necessidade de uma pergunta a ser respondida pelo conceito, que sabe que toda explicação é, por definição, provisória e parcial. Como caixa de ferramentas, o conceito deve servir como instrumental das nossas práticas; se assim não serve, deve ser descartado (DELEUZE; FOUCAULT, 1979). Como "máquina de guerra", o conceito é ferramenta de atuações micropolíticas, práxis de resistência e de engendramentos capazes de fomentar estratégias de ressonância dessas atuações no outro e em nós mesmos.

Logo, assume-se o posicionamento ético-estético de Deleuze em estabelecer novas formas de se relacionar com conceitos: "assim como um artista toma de seus predecessores e de seus contemporâneos os traços que lhes convêm, convido meus leitores a pegar e a rejeitar livremente meus conceitos" (GUATTARI, 1992, p. 23).

Semelhante à arte que produz sensibilidades, a filosofia fabrica conceitos que exigem um instrumental intuitivo estético similar à sensibilidade artística (DELEUZE; GUATTARI, 1992). Admitindo o paradigma estético na formulação e elucidação dos fenômenos sociais, percebemos que as máquinas de fabricação da realidade são de ordem criativa, porque engatilham a construção do novo a partir do caos de agenciamentos fluidos. Trata-se de conduzir a construção do real para espaço e tempo diversos, não habituais, produção de modos de sentir e perceber (perceptos e afectos) distanciados dos quadros de referência pré-formatados, condução a uma nova potência estética de sentir.

Sendo assim, não é possível conceber a teoria como arcabouço enjaulado, que não repercute e que não produza faíscas dialógico-estéticas - como um fazer da diferença e da alteridade. Não existe na teoria pretensão totalitária, mas usos totalitários das elaborações teóricas. Não há teoria, mas somente ação da teoria e ação da prática (DELEUZE; FOUCAULT, 1979), tornando preferível uma teoriza-ação.

Tendo em vista que os conceitos são ferramentas que possibilitam desemaranhar a rede que sustenta diferentes versões do real, é preciso compreender suas limitações para não opor teoria e prática, pesquisa e intervenção. $\mathrm{O}$ cartógrafo que acompanha o mapa ou o artista que desenha a realidade estética entende que a teoria é a porta de acesso ao engajamento político em um mundo cognoscível, compartilhando territórios existenciais que não se limitem ao "sobrevoo conceitual" sobre a realidade investigada (ALVAREZ; PASSOS, 2010).

Frente a este panorama, interroga-se sobre as relações entre a criação conceitual e algumas questões imanentes ao campo da Saúde Coletiva. O paradoxo se instauraria apenas se tomássemos a filosofia como exercício da transcendência, arborescência e reminiscência, distanciada do fazer estético da teoriza-ação.

\section{Panorama das incursões conceituais em saúde coletiva}

A Saúde Coletiva trata-se de um campo de saber, âmbito de práticas e área de exercício profissional, articulando um conjunto de práticas ideológicas, científicas, técnicas, políticas e econômicas, vinculadas a diferentes correntes de pensamento no contexto da reforma em saúde. No âmbito da produção de conhecimentos, proporciona reflexão teórico-epistemológica sobre o campo e suas disciplinas, a investigação científica e o desenvolvimento conceitual. No âmbito da ação política, associa-se a vetores como os movimentos sociais e à formulação e implementação do projeto da Reforma Sanitária Brasileira (PAIM, 2006).

Portanto, a Saúde Coletiva consiste em um campo dotado de historicidade, compreendendo os determinantes sociais do processo saúde-doença-cuidado e da organização dos serviços em Saúde. Como campo histórico, ultrapassa a definição inalcançável de saúde como situação de pleno bem-estar físico, mental e social, para definir saúde como estado de razoável harmonia entre o sujeito e sua própria realidade (SEGRE; FERRAZ, 1997).

A investigação teórica de Martins (2004) observa que a filosofia vem participando de inquirições no âmbito da Saúde Coletiva desde seu início através das questões tematizadas por Foucault e Canguilhem, seja como subsídio para reflexão de questões atinentes ao campo da saúde por meio de bases diversas como materialismo histórico, estruturalismo fenomenologia, dialética 
e positivismo. Para além das contribuições das grandes correntes do pensamento, o autor apresenta duas metodologias filosóficas em saúde: o método genealógico e o filosófico-conceitual. O método genealógico, de influência nietzschiana, exige do investigador a desconstrução de objetivações, valores e crenças solidificadas, possuindo larga aplicação nos contextos do nascimento do hospital, da constituição dos saberes disciplinares, do ingresso da medicina no hospital e das práticas discursivas no entorno da Saúde Mental. Por sua vez, o método filosófico-conceitual apresenta-se como possibilidade para abordar temas contemporâneos impensados nas correntes teóricas tradicionais, compreendendo o conceito como método propositivo de novos modos de estar no mundo.

Os estudos de Minayo (2001) problematizam os conceitos de estrutura, sujeito, determinismo e mudanças, pertinentes à interface entre saúde coletiva e ciências humanas e sociais, de modo a investigar o lugar da subjetividade, bem como a oposição ação-determinação nas correntes estruturalistas e nas abordagens compreensivas.

Canesqui (2003) realiza uma revisão dos referenciais teórico-metodológicos das pesquisas antropológicas e etnográficas no campo da saúde, concluindo haver maior interface entre as "novas sociologias" e a filosofia, surgidas a partir da crise dos sistemas globais de explicação. Estas novas sociologias contribuem para o campo da saúde através da retomada do sujeito da experiência vivida, a despeito das concepções até então hegemônicas sobre a determinação da ação.

Há no campo multifacetado da saúde uma diversidade sedimentada de saberes filosóficos, históricos, sociológicos e antropológicos no entorno de questões atinentes à saúde coletiva. Ressaltam-se também as investigações sobre a complementaridade das abordagens qualitativa e quantitativa em saúde, a partir dos embates entre as linguagens matemáticas e o mundo dos símbolos, significados e intencionalidades (MINAYO; SANCHES, 1993); os estudos sobre as bases teóricas e filosóficas do conceito de humanização e o seu lugar na reconstrução das práticas de saúde (AYRES, 2005); sobre as bases conceituais da produção da subjetividade do sujeito considerado louco, articulando-se as noções de protagonismo, alienação, produção de subjetividade e agenciamentos da subjetivação (TORRE; AMARANTE, 2001); as investigações sobre as racionalidades médicas e os novos paradigmas em saúde (LUZ, 2012); e os estudos que se esforçam na construção do conceito de Saúde Mental, uma lacuna teórica, a despeito da diversidade de modelos que versem sobre a doença mental (ALMEIDA FILHO; COELHO; PERES, 1999).

\section{Universalidade, território e desterritorialização de conceitos}

Cabe ressaltar que o SUS consiste em uma reformulação organizacional e política para as ações de saúde no Brasil. Regulado pela Lei no 8.080/1990 (BRASIL, 1990a), objetiva reordenar os serviços de saúde, abrangendo ações de promoção, proteção e recuperação da saúde. Alguns de seus princípios doutrinários são: universalidade, implicada com o direito à saúde para todos os cidadãos; integralidade, assistência integral aos aspectos biopsicossociais, bem como a garantia à continuidade do cuidado em diferentes níveis de atenção; e equidade, que pressupõe a luta pela superação das iniquidades sociais. Alinhado a tais imperativos, encontra-se o princípio de participação popular, aproximando os sujeitos dos mecanismos de controle de gestão e de fiscalização das políticas de saúde (SANTOS; QUINTANILHA; DALBELLO-ARAUJO, 2010).

Instrumentalizados pela caixa de ferramentas ético-estética, podemos problematizar os efeitos da compreensão dos princípios do SUS enquanto árvore-raiz. Sabemos que a realidade em sua concreta multiplicidade de formas desafia a universalidade destes princípios, ofertando realidades cruas em saúde, alheias às suas bases, traduzidas em segmentação do setor saúde, fragilização do matriciamento, baixa cobertura da Atenção Primária, desarticulação das redes de atenção à saúde e dos sistemas de informação, desigualdades regionais e vazios assistenciais em relação à cobertura populacional, etc.

Semelhante fenômeno de enraizamento conceitual ocorre com a noção de participação popular. Contraditoriamente, a incorporação jurídico-institucional da participação social (resultante das pressões populares) às instâncias colegiadas em saúde contribuiu para um arrefecimento destas mesmas forças político-sociais, através de movimentos de cooptação das potências reivindicatórias locais. Nesse sentido, a participação política e o controle social mostraram não depender exclusivamente de sua formulação legal, mas se concretizar no conjunto diverso das práticas, discursos e valores que atravessam o sistema de saúde (GUIZARDI; PINHEIRO, 2006).

Igualmente é possível conferir usos rizomáticos ou arborescentes em relação ao conceito de território em saúde. Se as práticas profissionais restringem-se à noção de território geográfico, a demanda permanece restrita ao caráter epidemiológico da população adscrita. A adoção por uma concepção nômade de "território vivo", por outro lado, convoca as equipes para intervenções não descontextualizadas da vida do usuário. São territórios existenciais porque representam espaços de circulação das subjetividades, dos enlaces e das trocas sociais (BRASIL, 2013).

Cabe mencionar que não se trata aqui de relativizar conceitos, mas agenciar a fabricação de práticas profissionais singulares, composição de novos territórios existenciais: escapes por desterritorialização, operando linhas de fuga necessárias ao trabalho em saúde.

No entanto, deve-se reconhecer o risco de desterritorialização dos conceitos, que é o de cair no vazio, extinguindo-se no sem sentido. Porém, desterritorializar implica em reterritorializar, movimentos indissociáveis e complementares. Compor novas formas de existir em curso, segundo a produção de territórios ético-estéticos estáveis, mas não estagnados. Deste modo, busca-se produzir desempenhos profissionais, institucionais e maquínicos em que se abandonam territórios pré-formatados, 
sem a pretensão de produzir o absoluto, compreendendo que cada prática encontra respostas apenas para os seus próprios problemas singulares.

Assim, coloca-se como questão a fabricação de profissionais pensantes segundo movimentos de autopoiese, porque o pensamento é condição para a criação do inusitado, capazes de romper com o preexistente e formular um novo possível. Novos arranjos que colocam à frente os desafios do cotidiano na oferta dos serviços e ações de saúde:

A universalização, todavia não quer dizer somente a garantia imediata de acessos às ações e aos serviços de saúde. A universalização, diferentemente, coloca o desafio da oferta desses serviços e ações de saúde a todos que deles necessitem, todavia, enfatizando a ações preventivas e reduzindo o tratamento de agravos. (BRASIL, 2000, p. 30).

\section{Horizontes políticos e ético-estéticos na clínica antimanicomial}

Mas como pode a filosofia contribuir para a elucidação do sofrimento psíquico, entrelaçando conceitos que evidenciam os enunciados delirantes e os discursos transgressores? Pistas apontam para a necessidade de estudar o mapa da produção de adoecimento ou de saúde psíquica como um pintor em vias de pintar, e não como um geógrafo que sistematicamente desvela territórios já dados (DELEUZE; GUATTARI, 1997).

Para Foucault (1999), pode o discurso se apresentar como singular, terrível ou maléfico. Frente à experiência da loucura, são ativados os mecanismos sociais de exclusão e interdição do discurso, de modo que o louco, ao mesmo tempo em que é aquele em que o discurso não pode circular como os outros, é também o detentor de um discurso no qual continuamente recaem os aparatos do saber: nova separação, exercida através da confluência de ouvidos disciplinares modernos, que possam produzir pretensas verdades a partir de espaços de quadriculamento marginal.

A Psiquiatria acreditou falar da loucura a partir de uma objetivação patológica, quando, sub-repticiamente, lida com uma loucura amparada em uma ética do desatino, do desvario e da animalidade, pressupondo uma verdade a ser desvelada, enigma indecifrável aos olhos incautos. O louco como um fragmento de homem de sentido despedaçado. A ciência, mesmo a mais pretensamente objetiva, deixa transitar em sua órbita aquilo que é mitológico e moral (FOUCAULT, 1972).

Em oposição ao aparato manicomial, abre-se para o debate para a constituição de discursos e práticas desinstitucionalizantes, não restritos aos aspectos técnicos, jurídicos e legislativos, calcados na denúncia da violência e da mortificação exercidas pelos hospícios. A clínica antimanicomial estabelece-se na busca de novos devires, abrindo o campo da Saúde Mental para uma práxis voltada à construção de um lugar de cidadania para a loucura no cotidiano do território (AMARANTE, 1995; LOBOSQUE, 2007).

O profissional de saúde em exercício da clínica antimanicomial deve considerar as peculiaridades do sofrimento psíquico, não para efeitos de quadriculamento, determinando os espaços de sua manifestação, ou fazer incidir os aparelhos de captura do desejo sobre o que desvia da norma, mas para promover novas formas de ser e sentir. Trata-se da construção de uma clínica ampliada que possibilita os espaços coletivos permissivos para a abertura à alteridade, convocando a implicação dos contextos envolvidos com o familiar e o comunitário, fabricando sujeitos rizomáticos desinstitucionalizados. No caso da psicose, afirma Guattari (1992) que os registros existenciais envolvem uma dimensão de autonomia de ordem estética: os aparatos científicos e institucionais que incidem sobre os sujeitos, objetivando a serialização das formas de pensar segundo as formas paradigmáticas de lucidez, reificam a subjetividade, paralisando-a. Discute-se a necessidade de promover categorias estéticas de exercício da liberdade.

Assim, os atores da saúde consistem em dispositivos clínicos de produção de subjetividades capazes de provocar a diferença no panorama homogeneizante, instituído pelo modo de subjetivação capitalista (GUIMARÃES; MENEGHEL, 2003). Novas práticas podem ser tecidas através da formulação de paisagens onde a rotina do serviço não implique em modelização do cuidado, mas no desenvolvimento de intervenções singulares e comprometidas ético-esteticamente com a autonomização dos sujeitos.

Deste modo, abre-se para o entendimento de que a dinâmica do sofrimento psíquico, não deve recair no exame de uma suposta constituição intrapsíquica ou neurológica, mas na assunção radical do caráter produzido da subjetividade. Subjetividade esta compreendida como atravessada pela cultura de massa que produz indivíduos conforme sistemas de submissão cada vez mais dissimulados e sutis, imbricados nas formas de produção e consumo capitalista (GUATTARI; ROLNIK, 2011).

Tendo em vista esse panorama, a construção de uma rede de atenção à Saúde Mental não deve restringir sua discussão à velocidade da implantação dos serviços substitutivos, mas identificar forças que atuem como "desejos de manicômio", expressos pelos nossos desejos de dominar, classificar, oprimir e subjugar. Afinal, é possível a sobrevivência da lógica manicomial mesmo em uma sociedade que rompeu com a hegemonia jurídico-institucional dos manicômios. Neste contexto, cabe aos atores da saúde compreender que não basta desospitalizar os indivíduos dos muros manicomiais, mas também desinstitucionalizar os nossos modos de compreender e lidar com a loucura (LEMKE; GONÇALVES, 2008; ALVERGA; DIMENSTEIN, 2006).

Se o saber psiquiátrico se revela incompleto sobre a loucura, isso se deve não a um "vínculo frouxo" entre a teoria dos sistemas neurobiológicos e as manifestações clínicas, mas a um equívoco filosófico que pauta a doutrina médica. A concepção médica de transtornos psiquiátricos tende a transplantar o ideal de causalidade das doenças orgânicas e seus mecanismos de ação para as doenças psíquicas, partindo do dualismo entre as esferas física e psíquica (FOUCAULT, 1991). Logo, o desviante é aquele que descumpre a norma, ingressando em um processo de inclusão marginal: o sujeito do desvio é 
cooptado por um aparato técnico-científico de silenciamento do desejo, serializando sua forma de ser conforme as necessidades produtivas de mercado. A inclusão é perversa porque por muito tempo marginalizou e oprimiu em instituições totais. Assim, os transtornos mentais foram construídos pelo mesmo aparato institucional e científico que se propôs a curá-lo e expurgá-lo.

Estes saberes disciplinares, técnicas para assegurar a ordenação das multiplicidades humanas, reduziram o múltiplo ao Uno, objetivando fluxos que mecanizam os movimentos, determinam a relação dos corpos e os objetos e capturam o tempo dos homens, fazendo crescer a sua utilidade na medida em que cresce sua docilidade. A passagem do poder disciplinar pauta-se na forma de exame, que está no centro dos processos que fabricam o indivíduo e classificam suas diferenças e aptidões como efeitos de poder e saber, mesclando a vigilância hierárquica absoluta e o mecanismo da sanção normalizadora (FOUCAULT, 1987). Assim como as prisões e as escolas, os aparatos técnico-científicos em saúde não se isentaram completamente dos procedimentos disciplinares:

Os efeitos destes modos de subjetivação podem ser observados no que é suscitado no indivíduo, a partir do que denominamos de imagens da saúde do cotidiano: toda a parafernália técnica utilizada, as roupas brancas, os hospitais e seus muros, a disposição dos consultórios, os sons de sirenes e ambulâncias, as pessoas morrendo no chão dos hospitais e em filas de postos de saúde, reproduzindo um modo-de-ser individualista e de sociedade de classes na sociedade. (GUIMARÃES; MENEGHEL, 2003, p. 358).

Guattari e Rolnik (2011) apresentam perspectiva convergente quando anunciam a função produtora de subjetividade dos equipamentos do capitalismo, que não se reduzem a identificações materno-paterno. Trata-se de conexões maquínicas entre instâncias de produção econômica, mecanismos de controle e dominação psíquica, em movimentos de fagocitose dos afetos e perceptos daqueles que diferem dos esquemas predominantes: crianças, loucos...

De acordo com Campos (2010), em um mundo globalizado contemporâneo, espaços abertos substituem espaços fechados, possibilitando mecanismos de controle pautados no surgimento de métodos e estratégias como o marketing, resultado da supervalorização da dimensão econômica e dos aparelhos de modernização, em detrimento das demais ecologias.

Para compor novos territórios existenciais, é preciso substituir a concepção de individualidade e subjetividade pelo conceito de produção de subjetivação, abdicando dos agenciamentos coletivos de enunciação capitalista (GUATTARI; ROLNIK, 2011). Sendo construído, ressalta-se a relevância da autopoiese, subjetivação enquanto feitura de si-mesmo, que não girem sempre em torno de si, mas que se abram ao contato com o diverso (DELEUZE; GUATTARI, 1992).

\section{Tramas rizomáticas em saúde}

Deleuze e Guattari (1995) propuseram como modelo de pensamento nômade a concepção de rizoma. O conceito de rizoma implica admitir os fenômenos como movimentos contínuos e descontínuos, em seu fluxo e mobilidade imprevisível, sem verticalidades, o que implica na aceitação da pluralidade possível de linhas de fuga, modalidades de pensar e agir diferente (FERREIRA, 2008). Se as relações passam a ser encaradas como contínuo em ação, como processo onde as interações evitam o estabelecimento estático de hierarquias, traçam-se caminhos para efetivar, por exemplo, o matriciamento na rede de atenção à saúde, evitando o estanque da comunicação.

Entretanto, resta-nos a questão em aberto: será que a rede de atenção substitutiva ao manicômio, ao possibilitar a passagem do manicômio para a difusão microscópica dos mecanismos de controle que incidem sobre indivíduos a favor de uma suposta otimização no gerenciamento do cuidado, não resultou em novas formas mais sutis e menos visíveis de controle, mas ainda categorizando e esquadrinhando os sujeitos? Será que estamos utilizando o argumento de "promoção da vida a qualquer custo" para determinarmos, como fizeram os atores manicomiais, quais são as verdades, silenciando e desautorizando os sujeitos sobre o corpo que lhes compete?

Figueiró e Dimenstein (2010), ao cartografar diferentes intensidades presentes em um Centro de Atenção Psicossocial (CAPS), indicaram a ausência de práticas de ajuda mútua entre usuários e profissionais. Ao perseguirem os atores responsáveis pela produção maquínica de subjetividades apáticas, os autores compreenderam que a concepção terapêutico-clínica da equipe contribuía para a atuação de captura das identidades, promovendo infantilização e interrompendo os fluxos de emancipação dos usuários.

Logo, é possível identificar formas locais de banalização e injustiça social mesmo na rede substitutiva, comportamentos de tolerância e passividade frente às violências cotidianas, explicitadas em demonstrações públicas de apatia burocrática (GUIMARÃES; MENEGHEL, 2003). A clínica antimanicomial não deve ser compreendida como um fenômeno diretamente decorrente das estruturas institucionais, mas como resultado de uma polifonia maquínica, interações entre dispositivos computacionais, revolucionários, universos de referência incorporais (arte, música, credos, redes de apoio, tradições culturais, etc.) e outros tantos dispositivos do território que podem compor linhas de subjetivação (GUATTARI, 1992).

Por outro lado, Lemke e Gonçalves (2008) descreveram um relato de experiência de intervenção em situação de crise psíquica na Estratégia de Saúde da Família (ESF). Nesse relato, os autores indicam o percurso de estranhamento dos olhares habituais, ausentando-se da perspectiva técnico-cientificista para adentrar os espaços críticos de sensibilidade onde os atores se implicam. Foi através de vinculações com um arcabouço conceitual ético-político-estético que se possibilitou a superação parcial dos efeitos da dicotomização saúde-loucura presente no cuidado à saúde. Igualmente, puderam produzir matriciamentos menos arborescentes entre unidade de saúde e espaços comunitários. 
A investigação cartográfica das práticas de saúde nos possibilita o entendimento de que não há profissão essencialmente policialesca, mas práxis de resistência, criação, captura, cooptação, empoderamento, serialização, dentre outros vetores possíveis (GUATTARI; ROLNIK, 2011). Torna-se preciso salientar que propomos a cartografia como via de problematização dos instrumentos, compreendida por Regis e Fonseca (2012) como estratégia interventiva e exercício de produção do conhecimento que viabiliza a expansão de vida.

Efetivar tramas rizomáticas em saúde exige a subversão das relações pautadas na postura técnico-assistencial para noções que valorizem o encontro como propulsor da articulação de forças de potência coletiva. Reversão e criação conceitual como estratégias de agenciamento das potencialidades favoráveis à cidadania: teoriza-ação que acredita na composição estética e no compromisso ético dos territórios existenciais.

\section{Por uma estética de resistência...}

Acreditamos que questões várias em Saúde Coletiva suscitam discussões pertinentes ao campo filosófico. No campo da Saúde Mental, ressaltam-se os debates sobre a produção de subjetividade e as representações sociais dos agentes de saúde sobre normalidade e patologia, bem como a relação entre sujeito, protagonismo, cidadania e comunidade. A questão da construção conceitual em saúde exige a superação de perspectivas tecnocráticas para propor ecologias estéticas enquanto objeto de análise (GUATTARI, 1990). Não se trata de propor necessariamente novos paradigmas científicos capazes de abordar o objeto saúde-doença-cuidado, porque sabemos dos riscos de uma fé irrazoável na razão (NIETZSCHE, 2001).

A efetividade da rede de atenção substitutiva não depende apenas da reorientação da formação profissional, do financiamento do setor saúde e das demais questões elencadas no início do artigo. Exige também uma reorientação ético-estética da práxis profissional, localizando-se no compromisso com a cidadania: agenciamento da coletividade segundo os interesses da mesma, a partir da participação coletivizada nas políticas de saúde.

O campo da Saúde Mental aponta no sentido de que as barreiras para a efetivação de práticas desinstitucionalizantes se situam, sobretudo, nos desejos de aprisionamento e exclusão na assistência aos sujeitos desviantes (portadores de transtornos mentais, usuários crônicos de substâncias psicoativas...), dificultando a autopoiese dos usuários. No entanto, devemos considerar também que o campo da saúde é atravessado por uma sociedade onde as formas de ser são esquadrinhadas e serializadas segundo as leis de mercado e de consumo.

Neste panorama sociopolítico pouco otimista, preferimos seguir os caminhos apontados por Resende (2008) e pensar o corpo como campo de forças, como arte em vias de fabricação, máquina pulsante e desejante que ultrapassa seus próprios contornos porosos: arte da existência. Não cabendo apartar saúde da teorização filosófica e do papel político de seus atores sociais, resta enfatizar o caráter de co-construção dos agenciamentos ético-estéticos, possibilitando vislumbrar atuações micropolíticas de promoção de vida e resistência.

\section{Referências}

ALMEIDA FILHO, N.; COELHO, M. T. Á.; PERES, M. F. T. O conceito de saúde mental. Revista USP, n. 43, p. 100-125, 1999.

ALVAREZ, J.; PASSOS, E. Cartografar é habitar um território existencial. In: PASSOS, E.; KASTRUP, V.; ESCÓSSIA, L. (Org.). Pistas do método da cartografia: pesquisa-intervenção e produção de subjetividade. Porto Alegre: Sulina, 2010. p. 131-149.

ALVERGA, A. R.; DIMENSTEIN, M. A reforma psiquiátrica e os desafios na desinstitucionalização da loucura. Interface (Botucatu), Botucatu, v. 10, n. 20, p. 299-316, dez. 2006.

AMARANTE, P. Novos sujeitos, novos direitos: o debate em torno da reforma psiquiátrica. Cad. Saúde Pública, Rio de Janeiro, v. 11, n. 3, p. 491-494, set. 1995.

AYRES, J. R. C. M. Hermenêutica e humanização das práticas de saúde. Ciênc. saúde coletiva, Rio de Janeiro, v. 10, n. 3, p. 549-560, set. 2005.

BRASIL. Presidência da República. Casa Civil. Subchefia para Assuntos Jurídicos. Lei $n^{\circ} 8.080$, de 19 de setembro de 1990. Dispõe sobre as condições para a promoção, proteção e recuperação da saúde, a organização e o funcionamento dos serviços correspondentes e dá outras providências. 1990a. Disponível em: <http://www.planalto.gov.br/ccivil_03/leis/ 18080.htm>. Acesso em: 10 set. 2012.

BRASIL. Presidência da República. Casa Civil. Subchefia para Assuntos Jurídicos. Lei $n^{\circ}$ 8.142, de 28 de dezembro de 1990. Dispõe sobre a participação da comunidade na gestão do Sistema Único de Saúde (SUS) e sobre as transferências intergovernamentais de recursos financeiros na área da saúde e dá outras providências. 1990b. Disponível em: <http://www. planalto.gov.br/ccivil_03/leis/18142.htm>. Acesso em: 10 set. 2012.

BRASIL. Ministério da Saúde. Secretaria Executiva. Sistema Único de Saúde (SUS): princípios e conquistas. Brasília: Ministério Saúde, 2000.

BRASIL. Ministério da Saúde. Secretaria de Atenção à Saúde. Departamento de Atenção Básica. Caderno de atenção básicasaúde mental. Brasília: Ministério da Saúde, 2013.

CAMPOS, J. D. P. Cartografias na educação com a caixa de ferramentas da Saúde Mental coletiva. 2010. Trabalho de Conclusão de Curso (Especialização em Educação em Saúde Mental Coletiva) Programa de Pós-Graduação em Educação, Faculdade de Educação da Universidade Federal do Rio Grande do Sul, Porto Alegre, 2010.

CANESQUI, A. M. Os estudos de antropologia da saúde/ doença no Brasil na década de 1990. Ciência e Saúde Coletiva, Rio de Janeiro, v. 8, n. 1, p. 109-124, 2003.

DELEUZE, G.; GUATTARI, F. O que é a filosofia?. 3. ed. Rio de Janeiro: Ed. 34, 1992.

DELEUZE, G.; GUATTARI, F. Mil platôs: capitalismo e esquizofrenia. 2. ed. São Paulo: Ed. 34, 1995. v. 1.

DELEUZE, G.; GUATTARI, F. Crítica e clínica. 2. ed. São Paulo: Ed. 34, 1997. 
DELEUZE, G.; FOUCAULT, M. Os intelectuais e o poder. In: MACHADO, R. (Org.). Microfísica do poder. Rio de Janeiro: Graal, 1979. p. 69-78.

FERREIRA, F. T. Rizoma: um método para as redes? Liinc em Revista, Rio de Janeiro, v. 4, n. 1, p. 28-40, mar. 2008.

FIGUEIRÓ, R. A.; DIMENSTEIN, M. O cotidiano de usuários de CAPS: empoderamento ou captura?. Fractal, Rev. Psicol., Niterói, v. 22, n. 2, p. 431-446, maio/ago. 2010.

FOUCAULT, M. História da loucura na idade clássica. São Paulo: Perspectiva, 1972.

FOUCAULT, M. Vigiar e punir: nascimento da prisão. Rio de Janeiro: Vozes, 1987.

FOUCAULT, M. Doença mental e psicologia. Rio de Janeiro: Tempo Brasileiro, 1991.

FOUCAULT, M. A ordem do discurso: aula inaugural no Collège de France. 5. ed. São Paulo: Loyola, 1999.

GUATTARI, F. As três ecologias. 7. ed. São Paulo: Papirus, 1990.

GUATTARI, F. Caosmose: um novo paradigma estético. Rio de Janeiro: Ed. 34, 1992.

GUATTARI, F.; ROLNIK, S. Micropolitica: cartografias do desejo. 11. ed. Rio de Janeiro: Vozes, 2011.

GUIMARÃES, C. F.; MENEGHEL, S. N. Subjetividade e saúde coletiva: produção de discursos na re-significação do processo saúde-doença no pós-moderno. Rev. Mal-Estar Subj., Fortaleza, v. 3, n. 2, p. 353-371, set. 2003.

GUIZARDI, F. L.; PINHEIRO, R. Dilemas culturais, sociais e políticos da participação dos movimentos sociais nos conselhos de saúde. Ciênc. saúde coletiva, Rio de Janeiro, v. 11, n. 3, p. 797-805, set. 2006

LEMKE, R. A.; GONÇALVES, S. E. Relato de uma experiência de intervenção em crise psíquica na estratégia de saúde da família. Boletim da Saúde, Porto Alegre, v. 22, n. 1, p. 49-55, jan./ jun., 2008.

LOBOSQUE, A. M. A reforma psiquiátrica que queremos: por uma clínica antimanicomial. Belo Horizonte: ESP-MG, 2007.

LUZ, M. T. Novos saberes e práticas em saúde coletiva: estudos sobre racionalidades médicas e atividades corporais. 3. ed. São Paulo: Hucitec, 2012.

MARTINS, A. Filosofia e saúde: métodos genealógico e filosófico-conceitual. Cad. Saúde Pública, Rio de Janeiro, v. 20, n. 4, p. 950-958, ago. 2004.

MINAYO, M. C. S. Estrutura e sujeito, determinismo e protagonismo histórico: uma reflexão sobre a práxis da saúde coletiva. Ciênc. saúde coletiva, Rio de Janeiro, v. 6, n. 1, p. 7-19, 2001.

MINAYO, M. C. S.; SANCHES, O. Quantitativo-qualitativo: oposição ou complementaridade?. Cad. Saúde Pública, Rio de Janeiro, v. 9, n. 3, p. 239-262, set. 1993.

NIETZSCHE, F. A gaia ciência. São Paulo: Companhia das Letras, 2001.

PAIM, J. S. Desafios para a saúde coletiva no século XXI. Salvador: EDUFBA, 2006.
PAIM, J. S. Uma análise sobre o processo da reforma sanitária brasileira. Saúde em Debate, [S.1.], v. 33, n. 81, p. 27-37, 2009.

REGIS, V. M.; FONSECA, T. M. G. Cartografia: estratégias de produção do conhecimento. Fractal, Rev. Psicol., Niterói, v. 24, n. 2, p. 271-286, maio/ago. 2012.

RESENDE, C. A escrita de um corpo sem órgãos. Fractal, Rev. Psicol., Niterói, v. 20, n. 1, p. 65-76, jan./jun. 2008.

SANTOS, K. L.; QUINTANILHA, B. C.; DALBELlOARAUJO, M. A atuação do psicólogo na promoção da saúde. Psicol. teor. prat., São Paulo, v. 12, n. 1, p. 181-196, 2010.

SEGRE, M.; FERRAZ, F. C. O conceito de saúde. Rev. Saúde Pública, São Paulo, v. 31, n. 5, p. 538-542, out. 1997.

TORRE, E. H. G.; AMARANTE, P. Protagonismo e subjetividade: a construção coletiva no campo da saúde mental. Ciênc. saúde coletiva, Rio de Janeiro, v. 6, n. 1, p. 73-85, jan. 2001.

Recebido em: 22 de outubro de 2012 Aceito em: 25 de março de 2015 